\title{
Assessment of monthly economic losses in Wuhan under the lockdown against COVID-19
}

\author{
Shibing You ${ }^{1 凶}$, Hengli Wang ${ }^{1}$, Miao Zhang ${ }^{1}$, Haitao Song $\mathbb{1}^{2 凶}$, Xiaoting $\mathrm{Xu}^{1} \&$ Yongzeng Lai ${ }^{3 凶}$
}

With the outbreak of COVID-19 in Wuhan, aggressive countermeasures have been taken, including the implementation of the unprecedented lockdown of the city, which will necessarily cause huge economic losses for the city of Wuhan. In this paper, we attempt to uncover the interactions between epidemic prevention and control measures and economic-social development by estimating the health loss and meso-economic loss from a human-oriented perspective. We implemented a compartmental model for the transmission dynamics and health burden assessment to evaluate the health losses, then estimated the direct and indirect economic losses of industries using the Input-Output model. Based on these estimates, the first monthly health losses and meso-economic losses caused by the lockdown was assessed. The overall policy effect of the lockdown policy in Wuhan was also investigated. The health loss and meso-economic losses are used to evaluate the health burden and loss of residents' mental health, the direct economic loss of several worst-hit industries, and the indirect economic loss of all industries, respectively. Our findings reveal that the health burden caused by this pandemic is estimated to be 4.4899 billion yuan (CNY), and the loss of residents' mental health is evaluated to be 114.545 billion yuan, the direct economic losses in transport, logistics, and warehousing, postal service, food, and beverage service industries reach 21.6094 billion yuan, and the monthly indirect economic losses of all industries are 36.39661994 billion yuan caused by the lockdown. The total monthly economic losses during the lockdown reach 177.0413 billion yuan. However, the lockdown policy has been considered to reduce COVID-19 infections by $>180$ thousand, which saves about 20 thousand lives, as well as nearly 30 billion yuan on medical costs. Therefore, the lockdown policy in Wuhan has obvious long-term benefits on the society and the total economic losses will be at a controllable level if effective measures are taken to combat COVID-19.

\footnotetext{
${ }^{1}$ Wuhan University, Wuhan, China. ${ }^{2}$ Shanxi University, Taiyuan, China. ${ }^{3}$ Wilfrid Laurier University, Waterloo, Canada. ${ }^{凶}$ email: 00001839@whu.edu.cn; htsongmath@gmail.com; ylai@wlu.ca
} 


\section{Introduction}

he COVID-19 occurred in Wuhan, China at the end of 2019 and then it rapidly spread to all provinces in China and other countries in the world, and now it became a global pandemic as claimed by WHO. To prevent the spread of COVID-19, the central government of China and Wuhan launched an extraordinary national emergency response to lockdown the megacity. The isolation of the city that ranked the 42nd of the world, naturally caused a series of chain reactions and an enormous impact on almost all the aspects of the city, a metropolis with a population of over 10 million and a complete industrial system (Roosa et al. 2020). The economic impacts and losses caused by the lockdown must be evaluated scientifically, which is of unique and referential significance to the prevention and control of outbreaks of major emerging infectious diseases like COVID-19.

The current studies of COVID-19 focus on two folds, one is to understand the transmission mechanisms for prevention and control, and the other is the assessment of economic losses and public health burden due to the endemic of COVID-19 (Phillips 2003; Kaufmann et al. 1997; Xu et al. 2020). Based on the study about the ratio of cost and efficiency for COVID-19, combining with transmission models (Xu et al. 2020; Tang et al. 2020a; Tang et al. 2020b), the effectiveness of antiviral drugs is assessed and the economic losses caused by epidemics are estimated (Schmitt and Zacchia 2010; Lee et al. 2008). The interview survey was also carried out to assess the losses of absence from work due to the epidemic (Chen et al. 2011). Factories and industries, services departments, schools are also closed during the lockdown of the city (Lempel et al. 2009; Sadique et al. 2008). As such, CGE (Computable General Equilibrium) model is used regularly to assess the economic losses (Mckibbin, 2006; Knobler et al. 2004; Rose 2009; Giesecke et al. 2012).

The policy to lockdown a megacity for controlling the endemic of COVID-19 is unprecedented, and the assessment of the economic losses is challenging due to the complexity of the problem. In this paper, we will study the impact of fighting the virus on the city during the first month of the lockdown from January 23 to February 23, 2020, to evaluate the economic losses from the health and the meso-economic perspectives (Agüero and Beleche 2017). The health losses are estimated using the physical and mental health losses from the infection of the COVID-19, and the meso-economic losses emphasize on the direct and indirect economic losses of industries because of the lockdown (KeoghBrown and Smith 2008).

\section{Methods}

Data and materials. This is a data-driven modeling study. We use three types of data: the first is the reported cases of different health endpoints to assess the health burden, the second is related to business data of transport, logistics and warehousing, postal service, accommodation, food, and beverage service industries to assess the meso-economic losses of industries, and the last is the supporting data to evaluate the health losses and the meso-economic losses. This research was solely based on the analysis of anonymized data, after taking several precautions to ensure appropriate protection of users' privacy and address any associated risks.

The health burden assessment is used to evaluate the economic losses in a month of different health endpoints under the lockdown against COVID-19 in Wuhan. The supporting data include a cumulative number of mild cases, severe cases, and deaths.

The data are from the web sites of the Chinese Center for Disease Control and Prevention (2020), reported cases of COVID-19 are from the World Health Organization (WHO) (2020a). COVID-19 Situation Report and reported cases of Hubei
Province from the Health Commission of the People's Republic of China and Hubei Province (2020b). Also, values of parameters of the transmission dynamical model are chosen from available published papers (Xu et al. 2020; Tang et al. 2020a; Tang et al. 2020b; Zhou et al. 2020; Guan et al. 2020; Lu et al. 2020; Newall et al. 2010) and the Handbook of Prevention and Treatment of the Pneumonia Caused by the Novel Coronavirus from Health Commission of China (2020a).

The data used for assessment of economic losses in a month of meso-economic industries under the lockdown against COVID19 in Wuhan include the monthly business data of airline, railway, expressway, public transportation, logistics and warehousing, postal services, accommodation, food, and beverage services. The key indicators include the number of flight cancellations, the number of seats per departure, the average flight load, the fixed cost of an aircraft and regular annual or monthly business income of railway, highway, metro, taxi and buses system of the city, logistics and warehousing, postal services, accommodation, food, and beverage services.

The data on meso-economic loss are collected from the following sources: website of Variflight (2020), the standards of International Civil Aviation Organization (ICAO) (2020), the annual revenue of Wuhan railway transportation (Shanghai Clearing House 2018b), Wuhan Expressway Toll Station's daily revenue (East Money database 2019), the annual revenue of Wuhan Metro Group (2019), annual report of Wuhan Bus Group (2018), annual report of Hubei Traffic Investment Group (2019), the website of Ministry of Transport of the People's Republic of China (2018), annual report of logistics and warehousing revenue in Wuhan (Wuhan Bureau of transportation 2018) and Wuhan statistical yearbook of 2018 (2018).

The health loss consists of the economic loss of patients' health and residents' mental health. The economic loss of patients' health is evaluated from treatment cost, recovery time, cost of lost time of different health endpoints for three categories of patients. The proxy variables of the economic loss of residents' mental health include monthly revenue of cultural entertainment services and state compensation standard for violating personal freedom. The industry linkage (calculated by the Input-Output table) is used to evaluate the meso-economic losses.

For the treatment cost of different health endpoints of infected individuals, we obtain the treatment cost value from China Public Health Statistical Yearbook. We also designed and carried out interview surveys of healthcare personnel associated with combating COVID-19. The treatment time and the average age of deaths due to infection are from the literature (Huang et al. 2020) and Handbook of Prevention and Treatment of the Pneumonia Caused by the Novel Coronavirus from the Health Commission of China (2020a). The time cost in hospital is computed by the daily average GDP per capita of Wuhan in 2018 from the Hubei Statistical Yearbook on Hubei Provincial Bureau of Statistics (2018). The monthly revenue of cultural entertainment services is computed by the annual revenue of this industry from the Wuhan Statistical Yearbook of 2018 (2018). The new state compensation standard for violating personal freedom was unveiled by China's Supreme People's Court and Supreme People's Procuratorate from its website (2020) and Wuhan's permanent and floating population at the end of the year is also got from Wuhan Statistical Yearbook of 2018 (2018). The industry linkage is calculated by the 149 sectors in the Input and Output table of nationwide in 2017 from the National Bureau of Statistics (2020).

\section{Model}

Constructing an evaluation system of monthly economic losses for the city. We base on our analysis of the concept of people- 


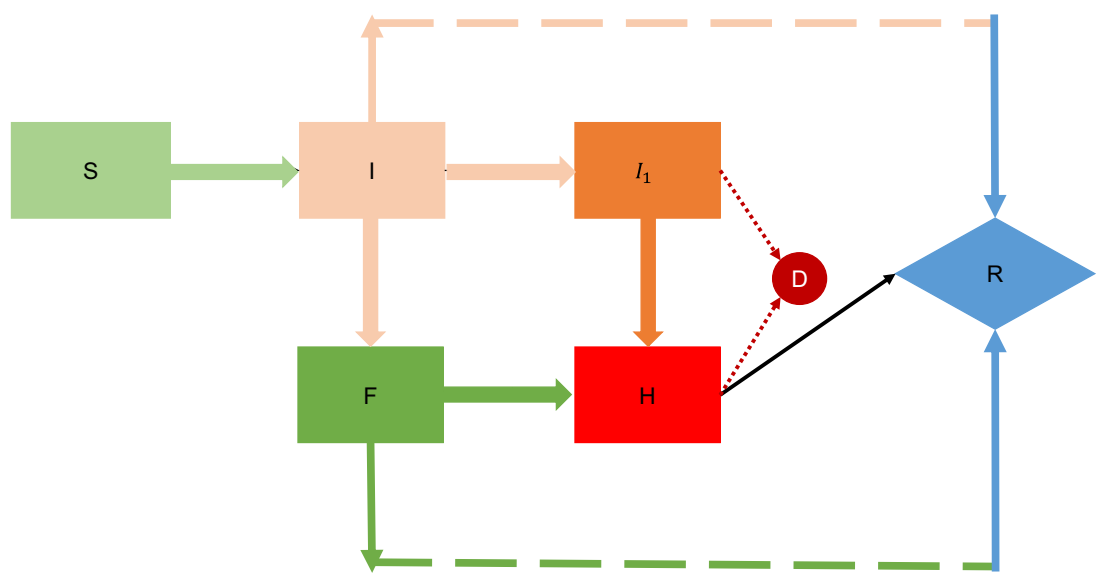

Fig. 1 The flow diagram of COVID-19 for our SIR model. Modified the original SIR-equation to account for a Susceptible (S) population state by introducing the mobile cabin hospitals $(F)$ and designated hospitals $(H)$ parameters.

oriented to find the balance between epidemic prevention and economic-social development. This paper constructs a comparative evaluation system of monthly economic loss of "Wuhan Lockdown" Policy from both health loss and industrial economic loss.

Monthly health loss evaluation: SIR model and health burden assessment. As an emerging and highly infectious disease (Xu et al. 2020), COVID-19 is causing losses in both the physical and mental health of the public at large (Huang et al., 2020). Although this study addresses only the 1-month residents' health losses, including physical health losses (health burden), and the mental health losses during the lockdown (Tang et al. 2020a), the approach can be applied to other situations with a longer period.

According to the Handbook, the diagnosed people are divided into three categories: mild, severe, and death (2020). There is a significant difference between direct and indirect economic losses, including time loss and the treatment of the three types of patients. However, there is no accurate official data on these three categories yet. To obtain the cumulative number of confirmed cases and the number of the three categories of confirmed cases, we established a SIR (Susceptible-Infected-Recovered) model and simulated the transmission of COVID-19 in the city (Harko et al. 2014; Hu et al. 2012; Liu et al. 2016).

Due to the lack of medical resources and sufficient beds in hospitals, designated hospitals only received severe patients. To relieve the massive shortage of doctors and medical resources, Huoshenshan Hospital and Leishenshan Hospital was built and observation wards were put into service on February 5. After that, mild patients were received into observation wards. Therefore, we consider the designated $s$ and observation wards bed ratio over two different stages of the epidemic. The first stage is from the date when the lockdown started on January 23 to the date when the first bed in observation wards opened to quarantine individuals on February 5, and the second stage is from February 5 to February 23. Also, we considered the effect of designated hospitals and mobile cabin hospital beds capacity on the transmission rate, the transfer rate from mild to severe patients, and death rate. Then the general population is divided into susceptible people $(S)$, mild patients $(I)$, severe patients $\left(I_{1}\right)$, mild patients in mobile cabin hospitals $(F)$, severe patients in designated hospitals $(H)$, Dead patients $(D)$, and recovered patients $(R)$ (Xu et al. 2020; Huang et al. 2020). Here, we assume that only mild patients can infect healthy people, while severe patients, who are quarantined, cannot infect susceptible people. The flow diagram is shown in Fig. 1.
Then the transmission dynamics of COVID-19 is determined by the following equations:

$$
\begin{aligned}
\frac{\mathrm{d} S(t)}{\mathrm{d} t}= & \frac{-\beta\left(b_{1}, I\right) S(t) I(t)}{S(t)+I(t)+R(t)}, \\
\frac{\mathrm{d} I(t)}{\mathrm{d} t}= & \frac{\beta\left(b_{1}, I\right) S(t) I(t)}{S(t)+I(t)+R(t)}-\alpha_{11}\left(b_{1}, I(t)\right) I(t) \\
& -\alpha_{12}\left(b_{1}, I(t)\right) I(t)-\gamma I(t), \\
\frac{\mathrm{d} F(t)}{\mathrm{d} t}= & \alpha_{11}\left(b_{1}, I(t)\right) I(t)-\alpha_{21}\left(b_{2}, F(t)\right) F(t)-\gamma_{f} F(t), \\
\frac{\mathrm{d} I_{1}(t)}{\mathrm{d} t}= & \alpha_{12}\left(b_{1}, I(t)\right) I(t)-\alpha_{31}\left(b_{2}, I_{1}(t)\right) I_{1}(t) \\
& -d_{1}\left(b_{2}, I_{1}(t)\right) I_{1}(t), \\
\frac{\mathrm{d} H(t)}{\mathrm{d} t}= & \alpha_{21}\left(b_{2}, F(t)\right) F(t)+\alpha_{31}\left(b_{2}, I_{1}(t)\right) I_{1}(t) \\
& -d_{h}\left(b_{2}, H(t)\right) H(t)-\gamma_{h} H(t), \\
\frac{\mathrm{d} R(t)}{\mathrm{d} t}= & \gamma I(t)+\gamma_{f} F(t)+\gamma_{h} H(t), \\
\frac{\mathrm{d} D(t)}{\mathrm{d} t}= & d_{1}\left(b_{2}, I_{1}(t)\right) I_{1}(t)+d_{h}\left(b_{2}, H(t)\right) H(t),
\end{aligned}
$$

where $b_{1}=\left\{\begin{array}{c}0, t<14 \\ b_{10}, t \geq 14\end{array}, b_{2}=\left\{\begin{array}{c}b_{21}, t<14 \\ b_{22}, t \geq 14\end{array}, \gamma_{f}=\left\{\begin{array}{c}0, t<14 \\ \gamma_{f 0}, t \geq 14\end{array}\right.\right.\right.$

$$
\begin{aligned}
\beta\left(b_{1}, I(t)\right) & =\frac{\beta_{0} I(t)}{b_{1}+I(t)}, \alpha_{11}\left(b_{1}, I(t)\right)=\frac{\alpha_{110} I(t)}{b_{1}+I(t)}, \\
\alpha_{12}\left(b_{1}, I(t)\right) & =\frac{\alpha_{120} I(t)}{b_{1}+I(t)}, \alpha_{21}\left(b_{2}, F(t)\right)=\frac{\alpha_{210} F(t)}{b_{2}+F(t)}, \\
\alpha_{31}\left(b_{2}, I_{1}(t)\right) & =\frac{\alpha_{110} I_{1}(t)}{b_{2}+I_{1}(t)}, d_{1}\left(b_{2}, I_{1}(t)\right)=\frac{d_{10} I_{1}(t)}{b_{2}+I_{1}(t)}, \\
d_{h}\left(b_{2}, H(t)\right) & =\frac{d_{h 0} H(t)}{b_{2}+H(t)}, \\
\alpha_{110} & =\left\{\begin{array}{c}
0, t<14 \\
\alpha_{110}, t \geq 14
\end{array}, \alpha_{210}=\left\{\begin{array}{c}
0, t<14 \\
\alpha_{210}, t \geq 14
\end{array}\right.\right.
\end{aligned}
$$


The effects of designated hospitals and mobile cabin hospital beds capacity on the transmission rate, the transfer rate from mild to severe patients, and death rate were considered as the parameters. The effect of mobile cabin hospitals beds capacity on the transmission rate, transfer rate from mild to severe patients and occupancy rate of mild patients in mobile cabin hospitals was denoted by the mobile cabin hospitals beds ratio $b_{1}$ corresponding to the mild patients. The effect of designated hospitals beds capacity on the hospitalization rate and death rate of severe patients were denoted by the mobile cabin hospitals ratio $b_{2}$ corresponding to severe patients (Shan and Zhu 2014; WHO 2020b).

Where $\beta$ is the contact transmission rate, $\alpha_{11}$ is the occupancy rate of mild patients in mobile cabin hospitals, $\alpha_{12}$ is the transfer probability from mild to severe. $\alpha_{21}$ is the transfer probability from mild to severe in mobile cabin hospitals, $\alpha_{31}$ is the hospitalization rate of severe patients.And $\gamma$ is the recovery rate of mild patients, $\gamma_{1}$ is the recovery rate of severe patients, $\gamma_{\mathrm{h}}$ is the recovery rate of severe patients in the hospital, $d_{1}$ is the mortality rate of severe patients, and $d_{\mathrm{h}}$ is the mortality rate of severe patients in the hospital. Here, the time unit $\mathrm{t}$ in the equation is defined as "day" of the event. Based on relevant epidemic data in Wuhan (2020), and the initial values on January 23, 2020 are chosen as follows: $S$ $(0)=55439, I(0)=269, F(0)=1000, I_{1}(0)=129, H(0)=494, D$ $(0)=23$, and $R(0)=31$. From the available literature on COVID19 (Tang et al. 2020b; Zhou et al. 2020; Guan et al. 2020) we assume that $\beta=0.813, \quad b_{21}=800, b_{10}=1500, b_{22}=1000, \alpha_{110}=0.7$, $\alpha_{210}=0.01, \alpha_{120}=0.04, \alpha_{310}=0.6$. Since the average incubation period is 7 days and the treatment time for mild patients is 10 days, so $\gamma=1 / 17$ and $\gamma_{\mathrm{fo}}=1 / 17$. The average treatment time for severe patients is 20 days, hence $\gamma_{\mathrm{h}}=1 / 20$ (Lu et al. 2020). The mortality rates of severe patients are $d_{10}=0.016$ and $d_{\mathrm{h} 0}=0.016$, respectively (Newall et al. 2010).

We then estimate the health burden attributable to patients' infection with the virus. The precondition of health burden assessment determines suitable health endpoints and gaining the number of infections in different health endpoints. The health endpoint is the final level of health risk caused by hazardous substances, and the final level can be classified based on the severity of diseases (Yao et al. 2020). A large number of domestic and foreign literature applied the health burden assessment to estimate the economic loss of health attributable to exposure to multiple air pollutants where the health endpoints were defined by the exposure-response function (Yao et al. 2020; Zhang et al. 2017; Maji et al. 2018). This method is used to estimate the economic v44 vloss of health due to this pandemic. Since the pathogenic mechanism of this pandemic is different from that of exposure to pollution and the SIR model built above would simulate to give the estimation of the numbers of the three categories of confirmed cases, the health endpoints in this paper are defined as the different levels of pulmonary infection caused by the COVID-19 and are divided into mild, severe, and death based on the computational results from the SIR model simulation. Thus,

$$
\begin{gathered}
L_{\mathrm{p}_{i}}=C_{\mathrm{p}_{i}}+\mathrm{GDP}_{P} \times T_{L_{i}}, \\
L_{i}=P_{i} \times L_{\mathrm{p}_{i}}, \\
L=\sum_{i=1}^{n} L_{i},
\end{gathered}
$$

where $i$ is the health endpoints, $L_{i}$ is the total cost of COVID-19 at health endpoint $i, C_{\mathrm{p}_{i}}$ is the unit cost of treatment cost at health endpoint $i, \mathrm{GDP}_{P}$ is the daily average GDP per capita in Wuhan Unit: Yuan/(person $\left.{ }^{*} d\right), T_{\mathrm{L}_{i}}$ is the cost of lost time due to disease at health endpoint $i, P_{i}$ is the number of people diagnosed at health endpoint $i$, and the sum of the economic losses at each health endpoint $\left(L_{i}\right)$ is the total attributable economic losses of the population $(L)$ under the outbreak ( $\mathrm{Lu}$ et al. 2016). Then, we calculate the total economic loss of health $(L)$, which is the health burden in a month of lockdown against COVID-19 in Wuhan.

To match the data of different health endpoints of COVID-19 with the data during the lockdown, we computed the cumulative cases using the SIR model, which would give the numbers of cumulative cases. Then, the monthly health burden can be estimated using the average treatment cost and the cost of lost time of different health endpoints.

Apart from physical health loss, the loss caused and associated with mental health due to that strict social distancing and home quarantine policy for combating COVID-19 prevented their public entertainment and cultural activities. Since the utility of consumption is hard to quantify, the revenues of cultural services were used to approximate and to evaluate the loss of mental health. Furthermore, the strict social distancing policy objectively restricted the personal freedom, mental loss caused by lockdown was evaluated based on the new state compensation standard for violating personal freedom unveiled by the Supreme People's Procuratorate of the People's Republic of China. Meanwhile, patients with acute or severe chronic diseases are unable to receive timely treatment, which leads to health loss by clinical exacerbation and increased mortality due to the lockdown policy. The lockdown also brought restrictions to transportation, social activities, and various constructions and could reduce mortality caused by traffic accidents, excessive drinking, cardiovascular diseases, industrial injury, etc. As these two aspects show opposite effects on the health of people and data availability limitation, these two indirect effects were ignored in our current studies.

Meso-economic loss evaluation: constructing the Input-Output (IO) model. Owing to the rapid spread of COVID-19, Wuhan city has been put under lockdown since January 23, 2020, and public transportation has been closed. The transportation industry is closely related to various industries, such as warehousing and retail, vacation tourism, accommodation and catering, cultural and entertainment industries, etc. Non-related upstream and downstream industries, such as the real estate industry, the financial industry, the construction industry, and other industries, seemed to be spared from COVID-19, but these industries also suffered direct or indirect losses. The effect of the lockdown in Wuhan on meso-economic industries is not limited to one industry. Therefore, we estimated the losses of directly affected industries, and then evaluated the indirect losses of other industries using the IO model ( $\mathrm{Li}$ et al. 2018).

Based on the IO table, we established the IO model incorporating the linkage of production and consumption to assess the economy of Wuhan. Since the 1970s, the IO model has been used to assess the effect of disasters, such as earthquakes and hurricanes on the economy. The results show that the IO model effectively solves the impact of a disaster on certain departments of the economic system and the assessment of related losses (Crowther et al. 2007; Tan et al. 2019). In this paper, the static IO model is used to evaluate the indirect economic losses among the industries (Crowther et al. 2007; Tan et al. 2019).

The correlations among the industries in the IO table can be expressed as:

$$
A X+Y=X
$$

That is, $\sum_{j=1}^{n} a_{i j} X_{j}+Y_{i}=X_{i}(i, j=1,2, \ldots, n)$, where $a_{i j}$ is the direct consumption coefficient, $X_{i}$ is the total output of sector $i$, and $Y_{i}$ is the final demand for sector $i$. Then the above formula 
can be transformed as:

$$
X=(I-A)^{-1} Y
$$

where $I$ is the identity matrix and $(I-A)^{-1}$ is the inverse matrix of Leontief.

Taking the sectional direct economic losses as losses in final products, $\Delta Y=\left(\Delta Y_{1}, \Delta Y_{2}, \ldots, \Delta Y_{n}\right)^{\mathrm{T}}$. Then the total product loss is:

$$
\Delta X=(I-A)^{-1} \Delta Y .
$$

The loss of indirect input is expressed by the reduction of intermediate input as $\Delta X-\Delta Y$.

To improve the accuracy of the indirect loss assessment of various departments, this paper uses the complete consumption coefficient for analysis. Let $B$ be a complete consumption coefficient matrix obtained by transforming the direct consumption coefficient matrix $\mathrm{A}$, then $B=(I-A)^{-1}-I$. Therefore, the total loss of the product can be further expressed as:

$$
\Delta X=(B+I) \Delta Y .
$$

Assume that $\Delta Y_{i}$ is the economic loss in the sector $I$ caused by COVID-19 and the final use of other sectors has no change. Then the total output of the entire economic system becomes

$$
\left(\begin{array}{l}
\Delta X_{1} \\
\Delta X_{2} \\
\cdot \\
\cdot \\
\Delta \dot{X} n
\end{array}\right)=\left(\begin{array}{c}
b_{1 i} \Delta Y_{i} \\
b_{2 i} \Delta Y_{i} \\
\cdot \\
\cdot \\
\cdot \\
b_{n i} \Delta Y_{i}
\end{array}\right)+\left(\begin{array}{c}
0 \\
0 \\
\cdot \\
\Delta Y_{i} \\
\cdot \\
0
\end{array}\right)
$$

where $b_{i j}(i, j=1,2, \ldots, n)$ are the complete consumption coefficients. Then the total output loss of sector $i$ is:

$$
\Delta X_{i}=b_{i i} \Delta Y_{i}+\Delta Y_{i},
$$

where $\Delta Y_{i}$ is the direct economic loss of sector $i$ and $b_{i i} \Delta Y_{i}$ is the indirect economic loss of sector $i$. The total product losses of other sectors are:

$$
\Delta X_{n}=b_{n i} \Delta Y_{i}, n \neq i
$$

\section{Results}

Empirical analysis of economic losses

The empirical analysis of health burden assessment and loss of residents' mental health evaluation in Wuhan on the lockdown against COVID-19. The SIR model was constructed to simulate the transmission of COVID-19 in Wuhan. The prediction results are shown in Fig. 2, where Cum I is the number of cumulative mild patients, Cum $I_{1}$ is the number of cumulative severe patients and Cum D is the counts of cumulative dead patients.

The simulation results show that the cumulative number of confirmed patients is 55,616 after the lockdown in Wuhan, among which the cumulative number of mild patients is 41,430 , the cumulative number of severe patients is 12,100 and the cumulative number of deaths is 2086 in the first month since January 23 to February 23, 2020.

Then health burden assessment was constructed to estimate the health losses of confirmed patients combining with the results from the SIR model. The cost of treatment in health burden assessment includes direct and indirect costs related to the patient during hospitalization, including the cost of diagnosis and treatment, medical costs, bed charges, nursing costs, time costs for suspension of work, transportation costs, accompanying costs, and so on. Due to the availability of data, we calculated the direct and indirect costs, including the cost of diagnosis and treatment during hospitalization, examination costs, bed charges, treatment costs, medical costs, and opportunity costs during hospitalization. Some hospitals survey the cost of treatment to obtain a reference average treatment cost for different symptoms of this new coronavirus infection. According to the China Health Statistics Yearbook in the past years and surveys on the treatment cost of some hospitals, we obtained the reference average treatment cost of different symptoms of COVID-19 (Sander et al. 2009; Barber et al. 2010; Christina et al. 2017; Hu and Chen 2019). According to the "Handbook of Prevention and Treatment of the

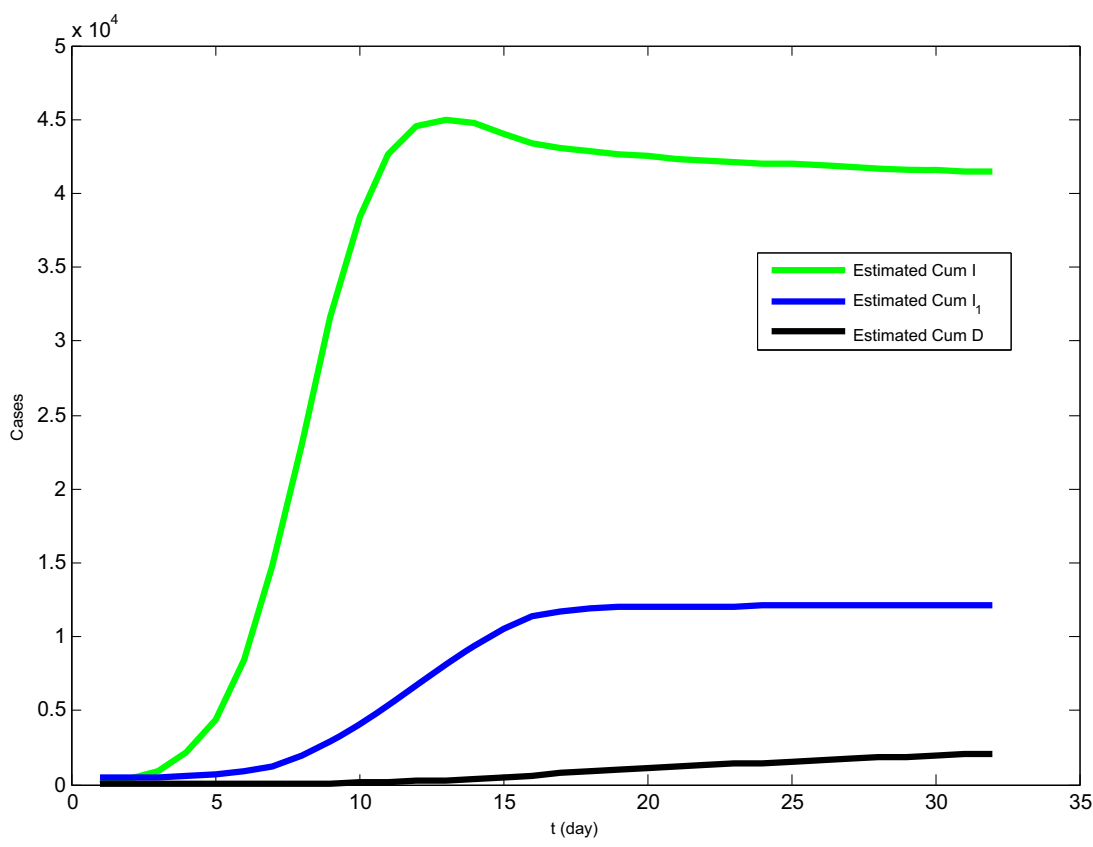

Fig. 2 Simulation results for the epidemics of COVID-19 in Wuhan in the first month after the lockdown of the city. The predicted results of estimated cumulative number of mild patients, severe patients and deaths are shown using the SIR model. 
Table 1 Number of confirmed cases and cost unit loss parameters at each health endpoint.

\begin{tabular}{|c|c|c|c|c|c|}
\hline $\begin{array}{l}\text { Health } \\
\text { endpoints }\end{array}$ & $\begin{array}{l}\text { Cumulative } \\
\text { quantity } P_{i}\end{array}$ & $\begin{array}{l}\text { The average cost of treatment } \\
C_{p_{i}} \text { (thousand yuan/per } \\
\text { person) }\end{array}$ & $\begin{array}{l}\text { Average time spent } \\
T_{L_{i}} \text { (day/per } \\
\text { person) }\end{array}$ & $\begin{array}{l}\text { Quarantine time spent } \\
T_{q} \text { (day/per person) }\end{array}$ & $\begin{array}{l}\text { The average value of the } \\
\text { time (yuan/per } \\
\text { person`day) }\end{array}$ \\
\hline Mild & 41,430 & 15 & 10 & 14 & 370.236 \\
\hline Death & 2086 & 300 & 1825 & 1 & \\
\hline
\end{tabular}

\begin{tabular}{|c|c|c|}
\hline Health endpoints & Costs per patient $L_{p_{i}}$ (yuan) & Total loss $L_{i}$ (yuan) \\
\hline Mild & $23,885.664$ & $989,583,059.5$ \\
\hline Severe & $103,588.024$ & $1,253,415,090$ \\
\hline Death & $1,077,131.87$ & $2,246,897,081$ \\
\hline \multicolumn{2}{|c|}{ The total loss L(yuan) } & $4,489,895,231$ \\
\hline
\end{tabular}

Pneumonia Caused by the Novel Coronavirus" issued jointly by the General Office of the National Health Commission of China and the Office of the State Administration of Traditional Chinese Medicine, we obtained the incubation period of the virus, the average treatment time and the average time cost for different health endpoints using the average age of death (Sadique et al. 2008). In reality, discharged patients would then be under quarantine at the expense of the government for 14 days before considered "fully recovered". Therefore, the time cost of 14 days' quarantine for patients should be counted. Where the value of time cost was measured by the average per capita GDP of Wuhan in 2018 , which was 135,136 yuan and it grows at an annual rate of $7 \%$ (2018). The average medical cost of different health endpoints was estimated using the disease cost method (Table 2). The above data is compiled and presented in Table 1.

Using the above data to calculate the health burden of confirmed patients' health in Wuhan, we obtain the results as shown in Table 2 and Fig. 3.

Table 2 and Fig. 3 shows that under the lockdown in Wuhan, the health burden is about 4.49 billion yuan in a month, where the economic loss caused by death is the largest part and it accounts for $>1 / 2$ of the total losses, which is consistent with the actual conditions. Although the relatively low cost of treatment occurs, the total cost of patients with mild pneumonia exceeds 989 million yuan due to the large scale of confirmed cases. The total costs of treatment for severe patients are about 1.253 billion yuan. Although the cumulative quantity of severe patients is much smaller than that of mild patients, the total amount of severe patients is higher because of its higher costs per patient.

According to the Statistical Yearbook of Hubei in 2019, the revenues of cultural services in Wuhan in 2018 reached 126.24497 billion yuan, equivalent to a monthly revenue of 10.5204142 billion yuan. We use this data as the proxy of mental distress loss caused by limiting culture and entertainment activities from January 23 to February 23, 2020.

According to China's State Compensation Law, Supreme People's Court (SPC) and Supreme People's Procuratorate set a new state compensation standard for violating personal freedom to be 346.75 yuan (about 49 U.S. dollars) per day (2020). The permanent residential population of Wuhan in 2019 was 11.212 million and the floating population was about 4 million. With 5 million people left Wuhan before the lockdown, about 10 million people were quarantined during the lockdown and the monthly mental loss of violating personal freedom was about 104.025 billion yuan. Therefore, the residents' health burden reached 4.4899 billion yuan and the economic loss of residents' mental health was about 114.5454142 billion yuan.

The empirical analysis of meso-economic loss assessment in Wuhan on lockdown against COVID-19. The IO model was used to estimate the direct and indirect economic losses in the transport, logistics and warehousing, postal service, accommodation, food, and beverage service industries and all industries in a month in Wuhan on lockdown.

The economic loss data of sectors affected directly is the precondition applied in the input-output model. In this paper, we took the transport, logistics and warehousing, postal services, accommodation, food and beverage services industries as the directly affected sectors in Wuhan under the lockdown, calculated the losses of the directly affected sectors, and estimated the indirect losses of all industries using the industry linkage calculated through the IO table (Wang et al., 2016).

Evaluation of direct economic losses in the transport, logistics and warehousing, postal service, accommodation, food, and beverage service industries. The economic losses in the transport, logistics and warehousing, postal service, accommodation, food, and beverage service industries, including economic losses caused by the suspension of flight, highway, public transportation, logistics and warehousing, postal service and all business in Wuhan were taken as the direct economic losses in the industries.

(1) Economic losses caused by flight cancellation:

In 2017, there were 99,300 departures, with a capacity of $17,773,200$ seats in Wuhan Tianhe Airport, which means 179 seats per departure. With an average flight load of $81 \%$, the actual capacity is 145 seats per shift (2019).

According to the standards of the International Civil Aviation Organization (ICAO), we took the medium-sized aircraft Boeing 737-300 as an example and calculated the annual fixed cost of an aircraft, including leasing fees, taxes, parking fees, aircraft maintenance costs, and corresponding aviation materials costs. The cost was 25 million yuan or about 70 thousand yuan per day. The economic loss of each flight cancellation is estimated to be $70+0.05 * 145=77.25$ thousand yuan in terms of 50 yuan/(person*flight) of economic loss of passengers due to flight cancellation.

Throughout the Spring Festival season between January 23 to February 22, 2020, the Spring Festival Travel Rush takes up about half the time, which is 15 days. There are 600 flights per day during the rush period and 340 flights per day at other times during the season. With the lockdown of Wuhan, the economic loss of all flight cancellations is $(340 * 15+600 * 15) * ; 77.25=1.089225$ billion yuan.

(2) Economic losses caused by the shutdown of railways, expressways and public transportation like subways, taxis, buses: 


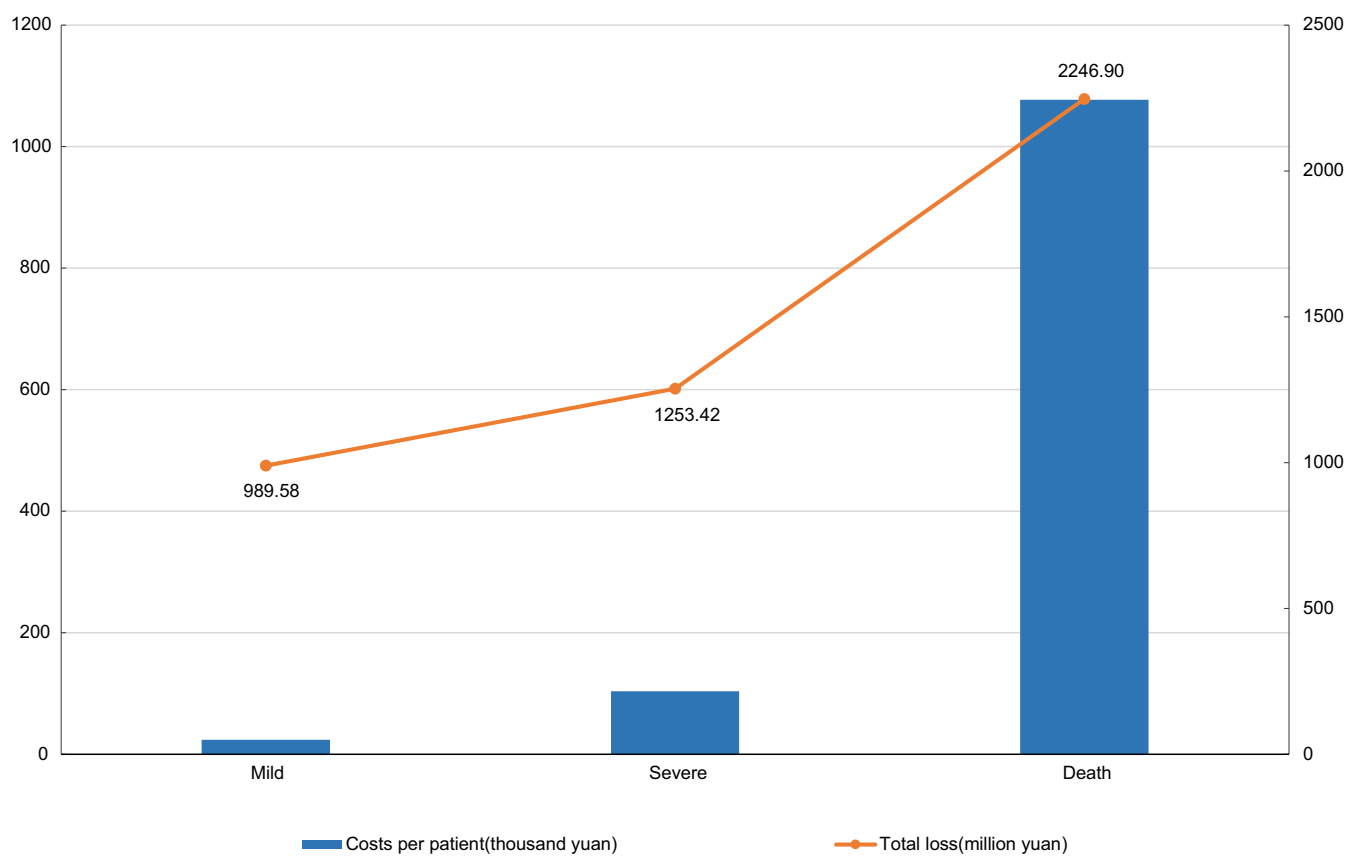

Fig. 3 Health burden of Wuhan against COVID-19 in a month. Health burden of different health endpoints (including mild, severe, and dead patients) are shown in the figure.

According to the annual revenue of 12.05679 billion yuan for Wuhan Metro Group in 2017, the estimated economic loss in Wuhan under the lockdown is 1.00473 billion yuan in 1 month.

By the 12.81 million yuan of average daily revenue of Wuhan railway transportation, 61.89 million yuan of Wuhan Expressway Toll Station's daily revenue, 9.3 million yuan of daily economic loss of taxi and to the statistics of Wuhan Public Group in 2018, we found that the estimated economic losses from railway transportation, expressway, public transportation like taxis and buses are 384.3 million yuan, 1.8567 billion yuan, 279 million yuan, and 811 million yuan, respectively. Therefore, the economic losses caused by the shutdown of railways, expressways, and public transportation are 384.3 million yuan and 3.95143 billion yuan, respectively.

(3) Economic losses of logistics and warehousing and postal service industries.

Since the annual revenues of logistics and storage were 153.209 billion yuan in 2018 in Wuhan and accounting for the 2-week closure of logistics during Spring Festival, the estimated economic loss in logistics and warehousing industry in Wuhan under the lockdown was about 6.56610 billion yuan in 1 month. According to the annual revenues of postal services in 2017 in Wuhan of 15.028 billion yuan, we estimated that the monthly economic loss of the postal services industry was about 1.25233 billion yuan. Therefore, the total economic losses in the two industries in Wuhan under the lockdown was about 7.818433 billion yuan in 1 month.

(4) Economic losses of accommodation, food and beverage service industries.

According to the revenues of accommodation, food, and beverage services industries in 2018 in Wuhan of 12.771 and 87.625 billion yuan, then the estimated economic loss in accommodation, food, and beverage services industries in Wuhan under the lockdown were 1.064 and 7.302 billion yuan in 1 month, respectively.
Based on the above evaluation of loss, the economic losses of the transport, logistics and warehousing, postal service, accommodation, food, and beverage service industries were about 21.60939 billion yuan during the 1-month Wuhan lockdown.

Evaluation of indirect economic losses in all industries due to economic losses in the transport, logistics and warehousing, postal service, accommodation, food, and beverage service industries. Based on the monthly economic loss of directly affected sectors in Wuhan under the lockdown and the 149 sectors in the IO table of nationwide in 2017, we assumed that the input-output relationships among various sectors of the national economy are stable and there is no significant difference between Wuhan and nationwide. Using the IO model, we estimated the monthly indirect economic losses of other industries caused by the monthly economic losses of transport, logistics and warehousing, postal service, accommodation, food, and beverage service industries during the lockdown in Wuhan. Considering the analysis method of the input-output relationship from direct and indirect economic losses, we chose the direct economic loss of the directly affected sectors as the final product loss, where $\Delta Y$ and $\Delta X-\Delta Y$ are defined the same as above. The complete consumption coefficient is introduced to obtain an accurate assessment of the indirect input loss of various sectors. The complete consumption coefficient is the quantity of the products in sector $i$ that needs to be consumed directly and indirectly for the production of final products per unit of sector $j$. As defined above, $B$ was used to represent the complete consumption coefficient matrix. Then $B=(I-A)^{-1}-I$ is the relationship between the complete consumption coefficient and the direct consumption coefficient. Thus, $B$ is obtained by the direct consumption coefficient matrix of each department given by the 149 sectors in the IO table of nationwide in 2017.

In this paper, we investigated the above hardest-hit industries, which have an indirect effect on all industries. Here, we only provided the complete-consuming coefficient of hardest-hit logistics and warehousing on all industries since that the complete-consuming coefficient of transport, postal service, accommodation, food, and beverage services industries on all 


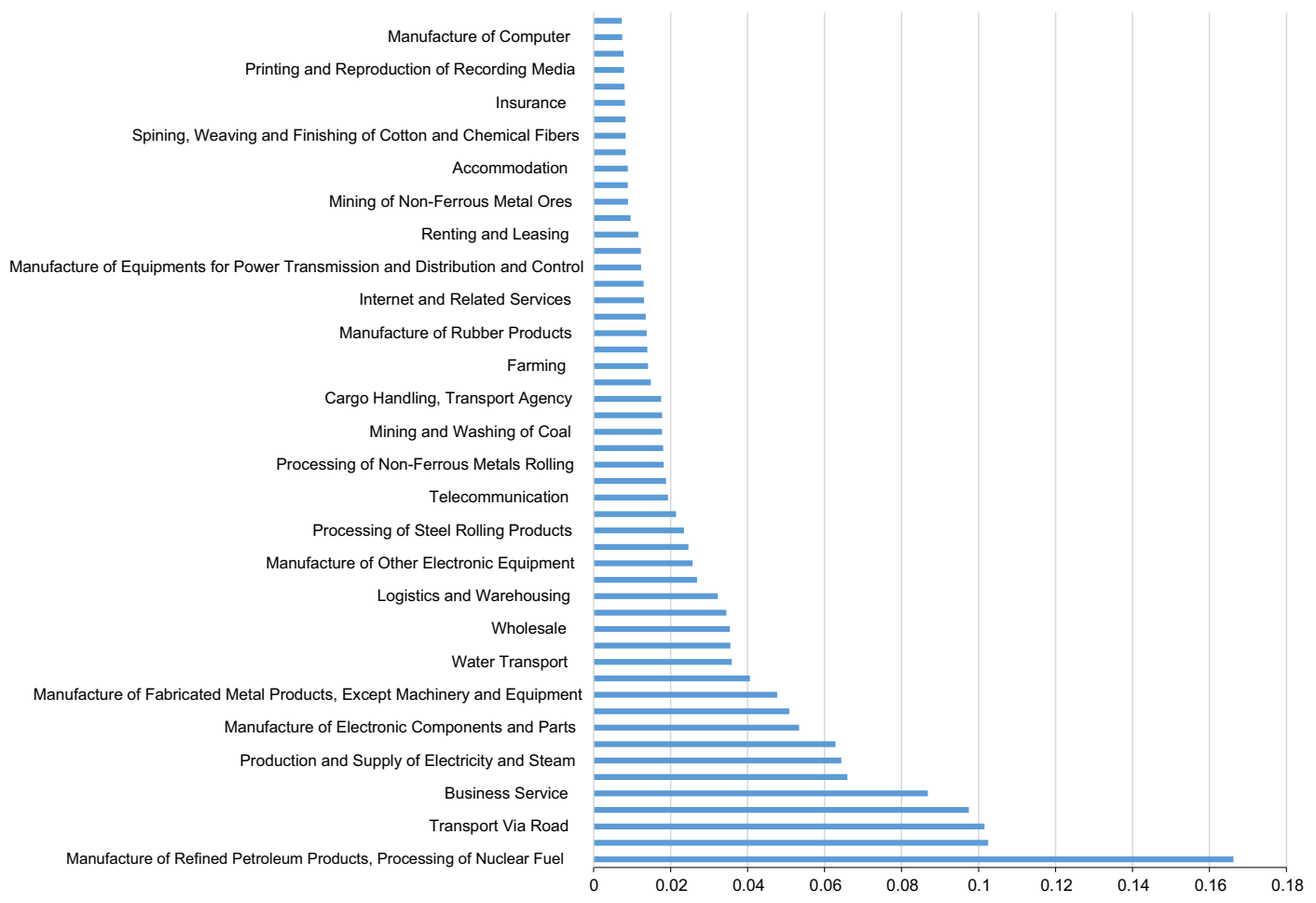

Fig. 4 Proportion coefficients of various industries affected by logistics and warehousing industry. Ranked by level of impact, top 52 most affected industries' complete consumption coefficients out of 149 industries are shown in the figure.

industries could be obtained similarly. We only demonstrated the top 52 most affected industries' complete consumption coefficients out of 149 industries as shown in Fig. 4.

Figure 4 shows that the most affected industry by the logistics and warehousing sector is the heavy chemical industry (in the secondary industry), followed by finance, business service, real estate, retail trade, and some service industries (tertiary industry).

On one hand, the total economic output value of Wuhan is still mainly derived from the secondary industry. On the other hand, tertiary industries should flourish during the Spring Festival, but the lockdown in Wuhan blocked all circulation. Based on the complete-consuming coefficient of logistics and warehousing on all industries, we obtained the indirect economic loss of this industry in 149 industries using the direct economic loss of this industry. Similarly, the indirect economic loss of transport, postal service, accommodation, food, and beverage service industries in 149 industries were evaluated using the same method. Taking the computation of indirect economic loss of logistics and warehousing industry on the manufacture of refined petroleum products and processing of nuclear fuel as an example, we obtained the indirect economic loss of 1.091486843 billion yuan of manufacture of refined petroleum products and processing of nuclear fuel caused by the economic loss of logistics and warehousing by the product of the direct economic loss and complete-consuming coefficient. Similarly, the indirect economic loss caused by transport via railway, public transport, air transport, postal, accommodation, food and beverage services on this industry were in turn 9.420318683 million yuan, 246.4772665 million yuan, 226.0048913 million yuan, 63.80720719 million yuan, 27.8101924 million yuan, 147.5145717 million yuan, respectively. Then the total indirect economic loss of manufacture of refined petroleum products and processing of nuclear fuel caused by the economic losses of the directly affected sectors was 1812.52129 million yuan (Table 3 ).
The total indirect economic loss of 149 sectors was calculated as shown in Table 3.

It follows from the above-estimated loss that the monthly indirect economic loss of 149 sectors caused by directly affected industries during the lockdown against COVID-19 in Wuhan was 36.39661994 billion yuan. The top ten of the most affected industries by transportation, logistics, and storage, post, accommodation, food, and beverage services were the manufacture of refined petroleum products and processing of nuclear fuel, monetary intermediation and other financial service industries, farming, business services, transport via road, extraction of crude petroleum and natural gas, production and supply of electricity and steam, manufacture of parts and accessories for motor vehicles, retail trade, and real estate. The indirect economic loss of each of these industries caused by lockdown exceeded 1 billion yuan. The economic loss of the secondary industry affected by the epidemic is relatively greater than that of the tertiary industry, possibly because the secondary industry still plays a main role in the economic system. In general, the economic loss of all sectors in the economic system is enormous during the lockdown in Wuhan.

Total economic losses calculation. The estimations reveal that the assessment of health burden is 4.4899 billion yuan, the loss of residents' mental health is estimated to be approximately 114.545 billion yuan, and the monthly direct economic losses of transport, logistics, and warehousing, postal service, accommodation, food, and beverage service industries are about 21.60939 billion yuan, and the monthly indirect economic losses of all industries are 36.39661994 billion yuan caused by the lockdown. To sum up, the total monthly economic losses reached 177.0413174 billion yuan under the lockdown due to COVID-19 in Wuhan.

Potential benefits of the lockdown policy in Wuhan against COVID-19. To better reflect the effectiveness of the policy, three periods were classified by major policy implementation dates that 
Table 3 Total product loss of sectors.

\section{Sectors}

Manufacture of refined petroleum products, processing

of nuclear fuel

Monetary intermediation and other financial service

Farming

Business service

Transport via road

Extraction of crude petroleum and natural gas

Production and supply of electricity and steam

Manufacture of parts and accessories for motor vehicles

Retail trade

Real estate

Fishery

Wholesale

Production and distribution of gas

Slaughtering and processing of meat

Manufacture of electronic components and parts

Processing of aquatic products

Animal production

Manufacture of fabricated metal products, except

machinery and equipment

Services to households, repair, and other services

Information technology services

Manufacture of crude and refined oils from vegetable

Manufacture of lifting and handling equipment

Manufacture of alcohol and alcoholic beverages

Manufacture of basic chemicals

Manufacture of grain mill products

Manufacture and casting of non-ferrous metals and

related alloys

Total: 36396.61994 million yuan
Loss/million yuan Sectors

1812.52129

1669.999383

1575.99144

1547.39021

1447.211474

1376.061407

1196.198534

1118.23097

1103.381289

1088.923504

901.5999004

870.1937226

728.9202493

651.9167348

649.803287

597.525887

574.802015

526.8098945

481.177

480.4121408

477.3311358

431.6198859

427.1081555

424.6285217

412.0942606

408.0007918
Food and beverage service

Manufacture of paper and paper products

Manufacture of plastic products

Manufacture of other general-purpose machinery

Mining and washing of coal

Logistics and warehousing

Manufacture of soft drinks and refined tea

products

Processing of steel rolling products

Manufacture of special chemical products

Water transport

Processing of other foods

Manufacture of rubber products

Manufacture of prepared animal feeds

Air transport

Manufacture of other food products n.e.c.

Manufacture of synthetic materials

Processing of non-ferrous metals rolling

Telecommunication

Manufacture of other electronic equipment

Cargo handling, transport agency

Manufacture of tobacco products

Manufacture of other transport equipment

Public transport

Renting and leasing

Postal service

Mining support activities and other mining and

quarrying n.e.c.
Loss/million yuan

392.285631

377.5854495

374.0356118

372.6409802

367.586247

339.6439639

327.0825538

312.8820655

307.4403502

302.2743938

301.3725889

299.006964

287.4780545

286.9515311

286.2442608

265.1430516

257.2645898

256.9645611

225.9475318

217.2261564

212.7696182

210.8796123

207.8337236

198.9865371

198.6842798

193.7999882
Table 4 2020.1.23-2020.2.23 proportion of patients in the three categories (\%).

\begin{tabular}{llll} 
Date & Light and normal & Critical & Death \\
\hline Jan 23rd-Feb 4, 2020 & 67.24 & 27.80 & 4.96 \\
Feb 5-Feb13, 2020 & 75.98 & 21.71 & 2.31 \\
Feb 14-Feb 23, 2020 & 75.79 & 21.72 & 2.49 \\
Total & 81.34 & 23.76 & 4.10 \\
\hline
\end{tabular}

could affect the virus transmission in Wuhan. The first period is from January 23 to February 4, when the local government blocked all outbound transportation from Wuhan and stopped public transportation and prohibited all vehicular traffic within the city. Additional social isolation and home isolation measures were also implemented. During the second period, between February 5 and February 13, the government implemented a policy of centralized quarantine and treatment of all confirmed and suspected cases in mobile cabin hospitals and 35 designated hospitals. The third period is between February 14 and February 23, when the government conducted door-to-door and individual-to-individual screening for all residents in Wuhan. The proportion of intensive, critical, and death cases decreased gradually in the three periods (Table 4 and Fig. 5). The policy benefits are obvious.

Simulations show that the effective reproduction number $R_{e}(t)$ in Wuhan reached 1.38 before January 23, peaked at 1.791 on January 24, and declined thereafter. The $R_{e}(t)$ was 0.0934 on February 4, 2020, then dropped to 0.03367 on February 6, 2020, and finally fell below 0.01651 by February 23 . We plot the trend of $R_{e}(t)$ (Fig. 6), which clearly shows that after the implementation of the "Lockdown" policy, the effective reproduction number of $R_{e}(t)$ decreased significantly and the outbreak was well controlled.

Besides, according to a previous study (Wang et al. 2020), the infected people in Wuhan would reach 227,989 in late February 2020 without lockdown or the specific measures in the above three periods, with an assumption of an epidemic spread of $R_{e}(0)=3.1$. Based on the per capita cost of treatment $(141,250$ yuan) for the three categories of patients mentioned above, the cost of treatment for epidemic patients alone would amount to 32.204 billion, while the direct economic loss of health is about 2142.5 million yuan in a month, it would add up to $>30.06$ billion without the lockdown.

Moreover, if the policy had not been implemented, the number of deaths would have reached 22,799, based on the percent of deaths as $10 \%$ from a calculation of case fatality rate (CFR) at an early stage of the epidemic (Chen et al. 2020), which means about additional 20,713 innocent lives will be taken. It can be seen that the effect of Wuhan's Lockdown is worthy of recognition.

\section{Conclusion and discussion}

This is a preliminary study of the cost for the first month of a locked-down city. Due to a major public health emergency, the lockdown was implemented on a metropolis with over 10 million people, which is unprecedented. How to evaluate the economic losses in the economic system caused by such a lockdown is a new topic that needs to be studied at present and in the future. In this paper, we used the SIR model, health burden assessment, and the IO model to quantify the economic losses in Wuhan under the lockdown. We gave a fundamental framework of assessing the 


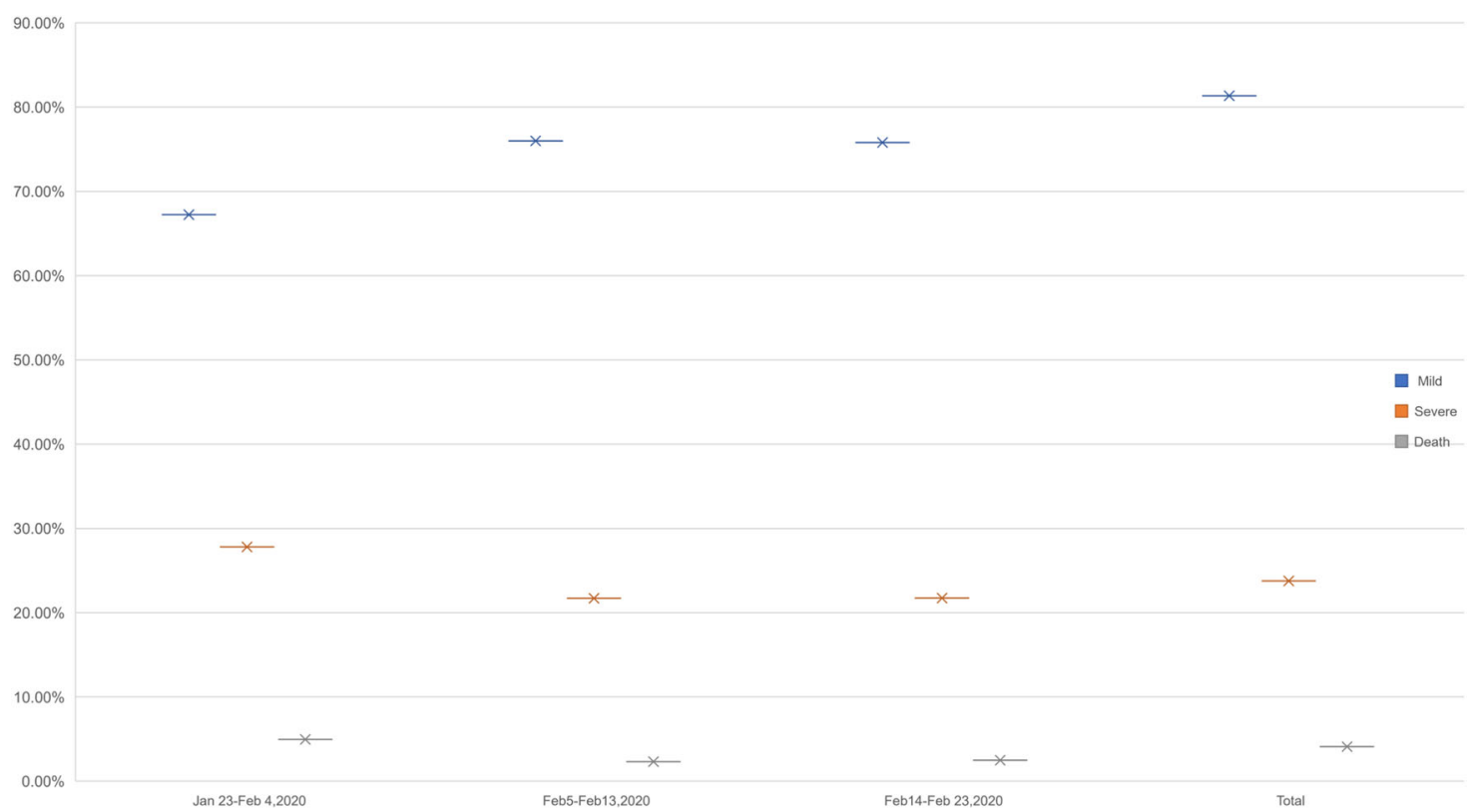

Fig. 5 Change in the proportion of patients in the three categories in Wuhan over three periods. The clinical severity of three categories was defined according to the Handbook of Prevention and Treatment of the Pneumonia Caused by the Novel Coronavirus.

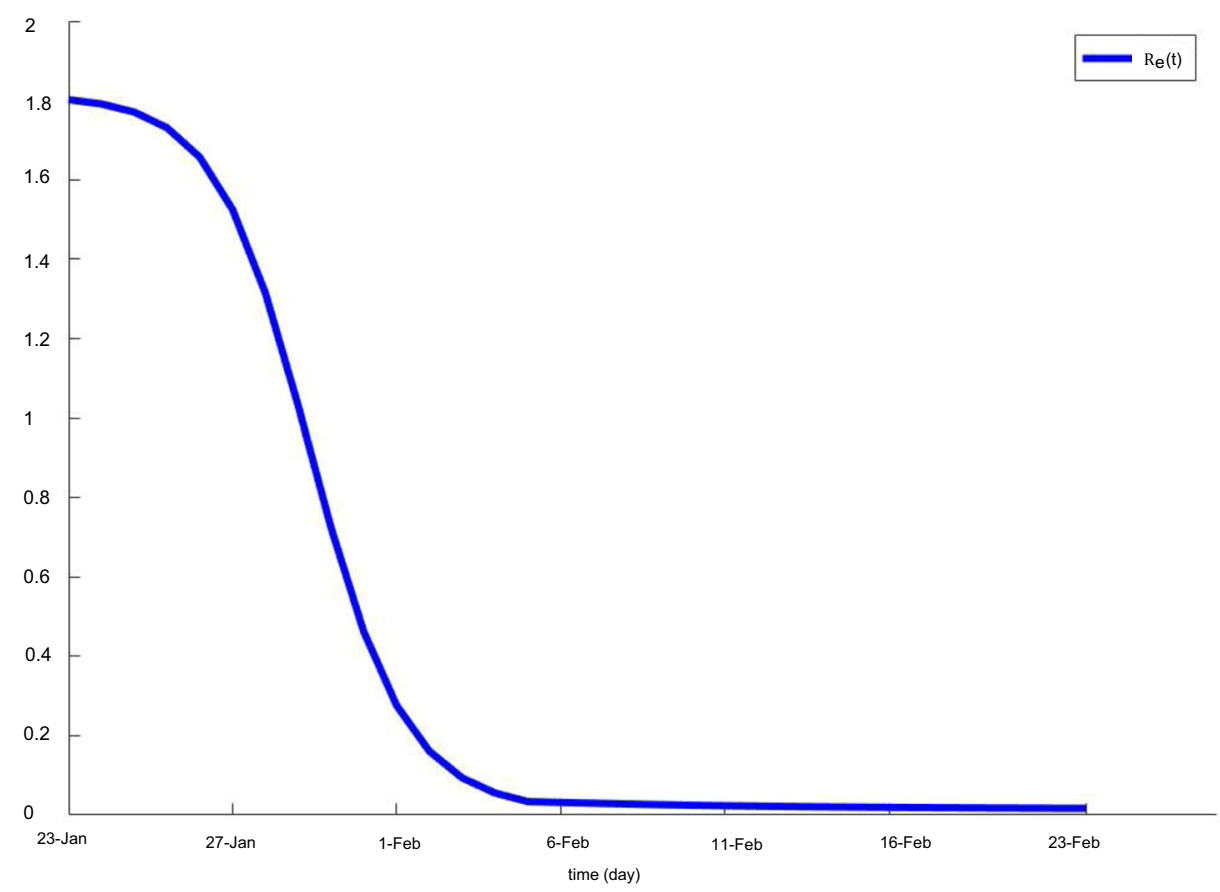

Fig. 6 Change of the effective reproduction number $\boldsymbol{R}_{\mathbf{e}}(\boldsymbol{t})$ of Wuhan over three periods. The $R_{\mathrm{e}}(t)$ is defined as the mean number of people who can be infected by a typical primary case at time $t$. The disease is persist when $R_{\mathrm{e}}(t)>1$, and the disease dies out when $R_{\mathrm{e}}(t)<1$.

economic loss in Wuhan during the lockdown and established the reference benchmark for the evaluation of monthly health losses and meso-economic losses in a metropolis with a population of over 10 million on lockdown.

The economic losses in Wuhan under the lockdown has negative effects on economic development, while the total economic losses will be controllable if COVID-19 is effectively contained. The lockdown in Wuhan causes the economic loss of residents' physical health and mental health of 119.0353094 billion yuan, which is $7.437 \%$ of Wuhan's annual GDP in 2019 and $35.454 \%$ of Wuhan's first-quarter GDP in 2019 (Wuhan's annual
GDP in 2019 is 1600.538 billion yuan, and that of the first-quarter is 335.748 billion yuan). The direct economic losses of the directly affected industries are 21.60939 billion yuan, which accounts for $1.35 \%$ of Wuhan's annual GDP in 2019, and $6.436 \%$ of Wuhan's first-quarter GDP in 2019. The total indirect economic losses of other industries are 36.39661994 billion yuan, constituting $2.274 \%$ of Wuhan's annual GDP in 2019 , and $10.8405 \%$ of Wuhan's first-quarter GDP in 2019. The monthly total economic losses are 177.0413174 billion yuan, making up $11.0614 \%$ of Wuhan's annual GDP in 2019 and $52.7304 \%$ of Wuhan's firstquarter GDP in 2019. Although the economic loss of each 
industry under the lockdown could be estimated, there is a basic macro judgment on the losses, which means that the economic aggregate of Wuhan will not experience a significant decline due to the short-term lockdown if the epidemic can be effectively contained.

It is advisable to pay attention to the characteristics of the industries impacted by the outbreak of COVID-19 and the lockdown of such a megacity. With the acceleration of the process of economic integration and the specialization of the industrial division of labor, the links among industrial sectors have become increasingly close, and a complex network of associations has been reshaped. The loss or impact of any industry will experience systematic risks. The empirical analysis of the IO model shows that the lockdown of Wuhan has a greater impact on the manufacture of refined petroleum products and processing of nuclear fuel, monetary intermediation and other financial services, farming, business service, transport via road, extraction of crude petroleum and natural gas than on other industries. Therefore, it is important to pay more attention to these industrial sectors that are highly sensitive to COVID-19. We must take targeted measures according to the characteristics of different sectors and develop scientific and effective post-epidemic recovery and development strategies to reduce and recover the economic losses caused by COVID- 19 .

The Lockdown of Wuhan provided extra time to prepare for the arrival of COVID-19 in >130 cities across China (Tian et al. 2020). Within 1 month of the city's Lockdown, Wuhan has experienced a significant decrease in the critical condition and death rates, as well as in the effective reproduction number. As these policies prevented greater economic losses and more deaths, the Wuhan Lockdown is a policy with significant potential benefits.

This research has focused on the health loss due to the outbreak of COVID-19 and the meso-economic losses of the industries due to the lockdown in Wuhan. Meso-economically, we only evaluated the direct economic loss of the transport, logistics and warehousing, postal service, accommodation, food and beverage service industries, and the indirect economic losses of 149 industries. The limitations of this research are the fact that we have not evaluated the direct economic losses of all mesoeconomic industry sectors, nor have we done the assessment from a macroscopic perspective of consumption, exports, and investment due to lack of data.

Currently, the pandemic of COVID-19 has become a global problem, the approach we used in this study can be applied to assess the economic losses of other cities, which supplies a rough estimation of the cost due to the pandemic.

\section{Data availability}

All data analyzed or generated during this study are publicly available.

Received: 27 March 2020; Accepted: 9 July 2020;

Published online: 31 July 2020

\section{References}

Agüero JM, Beleche T (2017) Health shocks and their long-lasting impact on health behaviors: evidence from the 2009 H1N1 pandemic in Mexico. J Health Econ 54:40-55. https://doi.org/10.1016/j.jhealeco.2017.03.008

Baidu Xinyu (2018) Annual Report of Wuhan Bus Group Co., Ltd in 2018. https:// xin.baidu.com/annualreport?pid $=29914674038286 \&$ year $=2018$. Accessed 23 Feb 2020

Barber LM, Schleier JJ, Peterson RK (2010) Economic cost analysis of the West Nile virus outbreak, Sacramento County, California, USA, 2005. Emerg Infect Dis 16:480-486. https://doi.org/10.3201/eid1603.090667
Chen NS et al. (2020) Epidemiological and clinical characteristics of 99 cases of 2019 novel coronavirus pneumonia in Wuhan, China: a descriptive study. Lancet 395(10223):507-513. https://doi.org/10.1016/S0140-6736(20)30211-7

Chen WC, Huang AS, Chuang JH (2011) Social and economic impact of school closure resulted from pandemic influenza A/H1N1. J Infect 62:200-203. https://doi.org/10.1016/j.jinf.2011.01.007

China Bond (2019) Wuhan Metro Group Co., Ltd.'s semi-annual financial report for 2019. https://www.chinabond.com.cn/cb/cn/ywcz/fxyfxdf/zqzl/qyz/cwbg/ 20191029/152999491.shtml. Accessed 23 Feb 2020

Chinese Center for Disease Control and Prevention (2020) Reported Cases of 2019nCoV http://2019ncov.chinacdc.cn/2019-nCoV/. Accessed 23 Feb 2020

Christina XC, Judith RB, Michael BN (2017) Economic burden of illness among persons with hemophilia B from HUGS Vb: examining the association of severity and treatment regimens with costs and annual bleed rates. Value Health 20:1074-1082. https://doi.org/10.1016/j.jval.2017.04.017

Crowther KG, Haimes YY, Taub G (2007) Systemic valuation of strategic preparedness through the application of the inoperability input-output model with lessons learned from Hurricane Katrina. Risk Anal 27:1345-1364. https://doi.org/10.1111/j.1539-6924.2007.00965.x

East Money database (2019) Business report of Hubei Chu Tian expressway co., ltd 2019 http://data.eastmoney.com/bbsj/600035.html. Accessed 24 Feb 2020

Giesecke JA, Burns WJ, Barrett A et al. (2012) Assessment of the regional economic impacts of catastrophic events: CGE analysis of resource loss and behavioral effects of an RDD attack scenario. Risk Anal 32(4):583-600. https://doi.org/ 10.1111/j.1539-6924.2010.01567.x

Guan WJ et al. (2020) Clinical characteristics of coronavirus disease 2019 in China. N Engl J Med 382:1708-1720. https://doi.org/10.1056/NEJMoa2002032

Harko T, Lobo FS, Mak M (2014) Exact analytical solutions of the SusceptibleInfected-Recovered (SIR) epidemic model and the SIR model with equal death and birth rates. Appl Math Comput 236:184-194. https://doi.org/ 10.1016/j.amc.2014.03.030

Health Commission of Hubei Province (2020b) Report of the epidemic situation in Hubei province. http://wjw.hubei.gov.cn/bmdt/ztzl/fkxxgzbdgrfyyq/. Accessed 23 Feb 2020

Hu M, Chen W (2019) Assessment of total economic burden of chronic hepatitis B (CHB)-related diseases in Beijing and Guangzhou, China. Value Health 12:589-592. https://doi.org/10.1111/j.1524-4733.2009.00636.x

Hu Z, Ma W, Ruan S (2012) Analysis of SIR epidemic models with nonlinear incidence rate and treatment. Math Biosci 238:12-20. https://doi.org/10.1016/ j.mbs.2012.03.010

Huang CL et al. (2020) Clinical features of patients infected with 2019 novel coronavirus in Wuhan, China. Lancet 395:497-506. https://doi.org/10.1016/ S0140-6736(20)30183-5

Hubei Provincial Bureau of Statistics (2018) Hubei Statistical Yearbook of 2018. http://tjj.hubei.gov.cn/tjsj/. Accessed 23 Feb 2020

International Civil Aviation Organization (2020) JAN 2020: Air Transport Monthly Monitor. https://www.icao.int/sustainability/Documents/Monthly Monitor-2020/MonthlyMonitor_January2020.pdf. Accessed 23 Feb 2020

Kaufmann AF, Meltzer MI, Schmid GP (1997) The economic impact of a bioterrorist attack: are prevention and post-attack intervention programs justifiable? Emerg Infect Dis 3:83-94

Keogh-Brown MR, Smith RD (2008) The economic impact of SARS: how does the reality match the predictions? Health Policy 88:110-120. https://doi.org/ 10.1016/j.healthpol.2008.03.003

Knobler S et al. (2004) Learning from SARS: preparing for the next disease outbreak-workshop summary. National Academies Press, Washington DC

Lee B et al. (2008) Simulating the economic impacts of a hypothetical bio-terrorist attack: a sports stadium case. J Homel Secur Emerg Manag 5(1):1-22. https:// doi.org/10.2202/1547-7355.1437

Lempel H, Epstein JM, Hammond RA (2009) Economic cost and health care workforce effects of school closures in the U.S. PLoS Curr. http://currents. plos.org/influenza/article/economic-cost-and-health-care-workforce-effectsof-school-closures-in-the-u-s/

Li L et al. (2018) Evaluation of future energy consumption on PM2.5 emissions and public health economic loss in Beijing. J Clean Prod 187:1115-1128. https:// doi.org/10.1016/j.jclepro.2018.03.229

Liu Q et al. (2016) Asymptotic behavior of a stochastic delayed SEIR epidemic model with nonlinear incidence. Physica A 462:870-882. https://doi.org/ 10.1016/j.physa.2016.06.095

Lu XC et al. (2016) Estimation of health and economic costs of air pollution over the Pearl River Delta region in China. Sci Total Environ 566:134-143. https:// doi.org/10.1016/j.scitotenv.2016.05.060

$\mathrm{Lu} R$ et al. (2020) Genomic characterization and epidemiology of 2019 novel coronavirus: implications for virus origins and receptor binding. Lancet Oncol 395:565-574. https://doi.org/10.1016/S0140-6736(20)30251-8

Maji KJ et al. (2018) PM2.5-related health and economic loss assessment for 338 Chinese cities. Environ Int 121:392-403. https://doi.org/10.1016/j. envint.2018.09.024 
Mckibbin WJ (2006) Global macroeconomic consequences of pandemic influenza. Paper available at http://www.lowyinstitute.org

Ministry of Transport of the People's Republic of China (2018) Number of taxi vehicles in provinces and cities of China. http://xxgk.mot.gov.cn/jigou/zhghs/ 201904/t20190412_3186720.html. Accessed 21 Feb 2020.

National Bureau of Statistics (2020) Input and Output table of nationwide in 2017. http://data.stats.gov.cn/files/html/quickSearch/trcc/trcc01.html. Accessed 20 May 2020

National Health Commission of the People's Republic of China (2020a) Handbook of Prevention and Treatment of the Pneumonia Caused by the Novel Coronavirus. http://www.nhc.gov.cn/jkj/s3577/202002/a5d6f7b8c48c451c87dba 14889b30147.shtml. Accessed 21 Feb 2020

National Health Commission of the People's Republic of China (2020b) Report of epidemic situation. http://www.nhc.gov.cn/xcs/xxgzbd/gzbd_index.shtml. Accessed 23 Feb 2020

Newall AT et al. (2010) Cost-effectiveness of pharmaceutical-based pandemic influenza mitigation strategies. Emerg Infect Dis 16:224-230. https://doi.org/ 10.3201/eid1602.090571

Phillips KA (2003) Prevention effectiveness: a guide to decision analysis and economic evaluation, 2nd edn. Oxford University Press, New York

Roosa K, Luo R et al. (2020) Real-time forecasts of the COVID-19 epidemic in China from February 5th to February 24th, 2020. Infect Dis Model 5:256-263. https://doi.org/10.1016/j.idm.2020.02.002

Rose AZ (2009) A framework for analyzing the total economic impacts of terrorist attacks and natural disasters. J Homeland Sec Emerg Manag 6(1):1-27. https://doi.org/10.2202/1547-7355.1399

Sadique MZ, Adams EJ, Edmunds WJ (2008) Estimating the costs of school closure for mitigating an influenza pandemic. BMC Public Health 8(1):135-141

Sander B, Nizam A, Garrison LP (2009) Economic evaluation of influenza pandemic mitigation strategies in the United States using a stochastic microsimulation transmission model. Value Health 12:226-233. https://doi.org/ 10.1111/j.1524-4733.2008.00437.x

Schmitt K, Zacchia NA (2010) Total decontamination cost of the anthrax letter attacks. Biosens Bioelectron 8:107-117. https://doi.org/10.1089/bsp.2010.0053

Shan C, Zhu H (2014) Bifurcations and complex dynamics of a SIR model with the impact of the number of hospital beds. J Differ Equations 257:1662-1688. https://doi.org/10.1016/j.jde.2014.05.030

Shanghai Clearing House (2018a) Annual Report 2018 of Hubei Traffic Investment Group Co., Ltd. http://www.shclearing.com/xxpl/cwbg/nb/201904/ t20190430_515236.html. Accessed 25 Feb 2020

Shanghai Clearing House (2018b) Annual Report of Hubei Railway Construction Group Investment Co., Ltd., 2018.21-23. https://www.shclearing.com/xxpl/ cwbg/nb/201904/t20190425_510350.html. Accessed 24 Feb 2020

The Supreme People's Procuratorate of the People's Republic of China (2020) The Supreme People's Procuratorate unveiled new state compensation standard for violating personal freedom. https://www.spp.gov.cn/spp/xwfbh/wsfbt/ 202005/t20200518 461183.shtml. Accessed 20 May 2020

Tan L et al (2019) Comprehensive economic loss assessment of disaster based on the CGE model and IO model-a case study on Beijing "7.21 Rainstorm" Int J Disaster Risk Reduct 39:101246. https://doi.org/10.1016/j.ijdrr.2019.101246

Tang B et al. (2020a) An updated estimation of the risk of transmission of the novel coronavirus (2019-nCov). Infect Dis Model 5:248-255. https://doi.org/ 10.1016/j.idm.2020.02.001

Tang B et al. (2020b) Estimation of the transmission risk of 2019-nCov and its implication for public health interventions. J Clin Med 9:462. https://doi.org/ $10.2139 /$ ssrn. 3525558

Tian HY et al. (2020) An investigation of transmission control measures during the first 50 days of the COVID-19 epidemic in China. Sci Am 368 (6491):638-642. https://doi.org/10.1126/science.abb6105

Vari Flight (2020) Development Report on Civil Aviation Airport in China 2019. https://data.variflight.com/. Accessed 23 Feb 2020

Wang HW et al (2020) Phase-adjusted estimation of the number of coronavirus disease 2019 cases in Wuhan, China Cell Discov 6(1):1-8. https://doi.org/ 10.1038/s41421-020-0148-0
World Health Organization (2020a) Coronavirus disease 2019 (COVID-19) Situation Report-34. https://www.who.int/docs/default-source/coronaviruse/ situation-reports/20200223-sitrep-34-covid-19.pdf?sfvrsn=44ff8fd3_2/. Accessed 23 Feb 2020

World Health Organization (2020b) World health statistics. https://www.who.int/ data. Accessed 23 February 2020

Wuhan Bureau of Statistics (2018) Wuhan Statistical Yearbook-2018. http://tij. wuhan.gov.cn/tjfw/tjnj/202004/P020200426461240969401.pdf. Accessed 23 February 2020

Wuhan Bureau of transportation (2018) Statistical Bulletin of Logistics in Wuhan in 2018. http://jti.wuhan.gov.cn/Item/10003953.aspx. Accessed 23 Feb 2020

$\mathrm{Xu}$ XT et al. (2020) Evolution of the novel coronavirus from the ongoing Wuhan outbreak and modeling of its spike protein for risk of human transmission Sci China Life Sci 63:457-460. https://doi.org/10.1007/s11427-020-1637-5

Yao MH et al. (2020) Estimating health burden and economic loss attributable to short-term exposure to multiple air pollutants in China. Environ Res 183:109184. https://doi.org/10.1016/j.envres.2020.109184

Zhang X et al. (2017) Socioeconomic burden of air pollution in China: provincelevel analysis based on the energy-economic model. Energy Econ 68:478-489. https://doi.org/10.1016/j.eneco.2017.10.013

Zhou T et al. (2020) Preliminary prediction of the basic reproduction number of the novel coronavirus 2019-nCoV. J Evid Based Med 13:3-7. https://doi.org/ $10.1111 /$ jebm.12376

\section{Acknowledgements}

We would like to thank Prof. Huaiping Zhu from York University for his help to improve the paper.

\section{Author contributions}

SY designed this study, HW, MZ, HS, and XX analyzed and explained the data, SY, HS, and YL wrote the paper, SY, HW, MZ, and XX contribute to the data collection. All authors read and approved the final manuscript.

\section{Competing interests}

The authors declare no competing interests.

\section{Additional information}

Correspondence and requests for materials should be addressed to S.Y., H.S. or Y.L.

Reprints and permission information is available at http://www.nature.com/reprint

Publisher's note Springer Nature remains neutral with regard to jurisdictional claims in published maps and institutional affiliations.

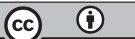

Open Access This article is licensed under a Creative Commons Attribution 4.0 International License, which permits use, sharing, adaptation, distribution and reproduction in any medium or format, as long as you give appropriate credit to the original author(s) and the source, provide a link to the Creative Commons license, and indicate if changes were made. The images or other third party material in this article are included in the article's Creative Commons license, unless indicated otherwise in a credit line to the material. If material is not included in the article's Creative Commons license and your intended use is not permitted by statutory regulation or exceeds the permitted use, you will need to obtain permission directly from the copyright holder. To view a copy of this license, visit http://creativecommons.org/ licenses/by/4.0/.

(C) The Author(s) 2020 